\title{
Hypertension and Diabetes: Contribution of the Kallikrein - Kinin System
}

\author{
Jagdish N. Sharma* and Parvathy Narayanan
}

Department of Applied Therapeutics, Faculty of Pharmacy, Health Sciences Centre, Kuwait University, Kuwait

\begin{abstract}
It is proposed here that a deficiency in bradykinin (BK) might be a significant factor in the pathophysiology of hypertension and type 2 diabetes. In this regard, it is suggested that the role of renal BK is to excrete the excess sodium. Reduction in the generation of renal BK may be the cause in the development of hypertension as a result of the accumulation of sodium in the body. Thus, the development of a compound having renal kallikrein-like activity may serve the purpose of excreting excessive sodium from the kidney in the treatment of hypertension. Transgenic mice over-expressing renal tissue kallikrein were hypotensive and administration of aprotinin, a tissue kallikrein inhibitor, restored the blood pressure (BP) of the transgenic mice. Recently, it has been proposed that tissue kallikrein gene delivery into various hypertensive models exhibits protection, such as reduction in high BP, attenuation of cardiac hypertrophy, inhibition of renal damage and stenosis. This may indicate the future of kallikrein gene therapy for hypertension, cardiovascular and renal pathology.
\end{abstract}

Keywords: Bradykinin system; Diabetes; Hypertension; Overview

\section{Introduction}

Cardiovascular diseases are the most common cause of mortality worldwide. Hypertension and diabetes are the two major risk factors in the development of cardiac hypertrophy, ischemic heart disease and cardiac failure. Previous studies have indicated altered activities of the BK-generating components in hypertension and diabetes [1]. BK is a pharmacologically active polypeptide that can promote both cardiovascular and renal function, for example, vasodilation, natriuresis, diuresis and release of nitric oxide (NO) [2,3]. In addition, $\mathrm{B}_{2}$ kinin receptors are present in the cardiac endothelial cells which may enhance the biosynthesis and release of NO. Sharma and Uma [4] demonstrated that reduced tissue kallikrein levels may be associated with the development of high BP in spontaneously hypertensive rats (SHR) and diabetic rats. BK may produce pharmacological effects via $\mathrm{NO}$ and cyclic GMP (cyclic guanosine mono phosphate) release [5].

Furthermore, it has been established that kinin has cardioprotective actions in myocardial ischemia and can prevent left ventricular hypertrophy (LVH) [3]. Also, transgenic mice carrying tissue kallikrein gene and over expressing tissue kallikrein had reduced BP [6]. NO synthase and renal tissue kallikrein are both involved in BP regulation $[7,8]$.

This update is intended to provide the readers, recent developments on the role of $\mathrm{BK}$ in hypertension and diabetes.

\section{Kallikrein Kinin System (KKS)}

$\mathrm{BK}$ is a pharmacologically active polypeptide, which is released in the tissues and body fluids as a result of enzymatic action of kallikreins on kininogens. The kinins include BK Arg-Pro-Pro-Gly-Phe-Ser-ProPhe-Arg), Kallidin (Lys-Arg-Pro-Pro-Gly-Phe-Ser-Pro-Phe-Arg) and methionyl-lysyl-BK (Met-Lys-Arg-Pro-Pro-Gly-Phe-Arg). Kallidin and methionyl-lysyl-BK are converted into BK by amino peptidases present in plasma and urine. BK is rapidly $(<15 \mathrm{sec})$ inactivated by circulating kininases. Once BK is released in the blood and body fluids, it may act on two different $B K$ receptors known as $B_{1}$ and $B_{2}$. The biological activities of $B K$ per se are mediated through $B_{2}$ receptor, as this receptor has a higher affinity towards these kinins. Likewise, Lys$\mathrm{BK}$ preferably binds to $\mathrm{B}_{2}$ receptor. The des-Arg metabolites of these kinins (i.e. des-Arg9-BK and des-Arg10-lys_BK) have a higher affinity for the $\mathrm{B}_{1}$ receptor.
Kininogens are multifunctional proteins derived mainly from alpha- 2 globulin. In humans the two forms of kininogens are high molecular weight kininogen (HMWK) and low molecular weight kininogen (LMWK). These kininogens vary from each other in molecular weight, susceptibility to plasma and tissue kallikreins and in their physiological properties [1]. They are synthesized in the liver and circulate in the plasma and other body fluids.

There are two forms of kallikreins known as tissue kallikrein and plasma kallikrein. Tissue kallikrein is found in various organs such as the kidney, heart and synovial tissue. The tissue kallikrein is synthesized in the cell as a precursor and converted into the active form by the cleavage of an amino terminal peptide [9]. Active tissue kallikrein acts on LMWK to release kallidin. Tissue and plasma kallikreins differ from one another in molecular weight, biological functions, physicochemical and immunological properties. The plasma kallikrein is present in circulation in an inactive form, which is known as plasma prekallikrein or Fletcher factor. This plasma prekallikrein is converted to active plasma kallikrein by activated Hageman factor (XIIa). Also factor XIIa can liberate BK from HMWK in the absence of plasma kallikrein. In addition, plasma kallikrein is able to convert inactive factor XII to XIIa by positive feedback reaction [9]. The majority of plasma prekallikrein circulates as a non-covalent complex with HMWK. Factor XIIa and factor XI circulate with HMWK in bound form. In this way, factor XI can be converted into XIa for the participation in the intrinsic coagulation cascade. Treatment of cells or cellular matrices with HMWK and plasma prekallikrein in the absence of factor XIIa generates plasma kallikrein activity [10]. Plasma kallikrein activity is generated following treatment of cells with factor

*Corresponding author: Jagdish N Sharma, Department of Applied Therapeutics, Faculty of Pharmacy, Health Sciences Centre, Kuwait University, PO Box 24923 Safat 13110, Kuwait, Tel: 24986530; Fax: 24986841; E-mail: j.n.sharma@hsc.edu. kw

Received October 17, 2011; Accepted December 15, 2011; Published December 19, 2011

Citation: Sharma JN, Narayanan P (2011) Hypertension and Diabetes: Contribution of the Kallikrein - Kinin System. J Diabetes Metab S4:004. doi:10.4172/2155-6156. S4-004

Copyright: (C) 2011 Sharma JN, et al. This is an open-access article distributed under the terms of the Creative Commons Attribution License, which permits unrestricted use, distribution, and reproduction in any medium, provided the original author and source are credited. 
Citation: Sharma JN, Narayanan P (2011) Hypertension and Diabetes: Contribution of the Kallikrein - Kinin System. J Diabetes Metab S4:004. doi:10.4172/2155-6156.S4-004

XIIa-deficient plasma, but not plasma prekallikrein-deficient plasma [11]. Activity of a partially purified plasma prekallikrein activator is not inhibited by factor XII-neutralizing antibodies and demonstrated negligible activity against factor XIIa substrates [12].

Furthermore, it is of interest to state that the tissue kallikreinkinin-system is the least complex of the two KKS as it only involves LMWK. However the plasma KKS is more complex, involving several molecules bound to the cell surface. The conversion of plasma prekallikrein into plasma kallikrein by factor XIIa only occurs ex vivo on non-physiological, negatively charged surfaces, such as glass and silica. It is now accepted that factor XII activation is not the initiating step in kallikrein-kinin activation, but instead is a secondary event which serves to increase the rate and extent of the reaction initiated by plasma kallikrein $[10,11]$.

In immunological reactions, the tissue proteoglycan and mast cell heparin might act as an initiating surface for initial activation of the Hageman factor [13]. It seems that the kinins may be generated in parallel with the formation of thrombin at inflammatory sites, since plasma prekallikrein can be activated by coagulant Hageman factor. The tissue kallikrein multigene family comprises closely related cluster of genes that vary in number between the different mammalian species: 24 genes have been identified in the mouse, 20 in the rat, 3 in humans and 3 in the hamster $[1,14]$.

Several restriction fragment length polymorphisms (RFLP) have been mapped in tissue kallikrein gene and their regulatory regions in SHR [15]. These findings may reflect a possible difference in the tissue kallikrein gene locus between SHR and normotensive Wistar-Kyoto (WK) rats. A tissue kallikrein RFLP has been indicated to co-segregate with high $\mathrm{BP}$ in the $\mathrm{F} 2$ offspring of SHR and normotensive Brown Norway rat crosses [14]. This finding strongly suggests a possibility of a close linkage between the kallikrein gene locus and the hypertensive phenotype of SHR.

Kininases, kinin inactivating enzymes, are present in the plasma, endothelial cells and in the tissues to regulate the physiological functions of the kinins in the body. These are known as kininase I, and kininase II [angiotensin converting enzyme (ACE)] and encephalinase. In plasma, kininase I cleaves the C-terminal argentine of $\mathrm{BK}$ to form des-Arg9-BK. Kininase II causes inactivation of BK by releasing pentapeptide (Arg-Pro-Pro-Gly-Phe) and tripeptide (Ser-Pro-Phe) fragments (Figure 1).

Interaction between kinins and their specific receptors can lead to activation of several second messenger systems. The BK receptor stimulation initiate the second messenger pathways, such as the arachidonic acid products and the activation of calcium sensitive systems [16]. The elevation of cellular inositol phosphates by BK involves G-protein coupled activation of phospholipase $A_{2}$ and $C$ that are used in the synthesis of eicosanoids [17]. It is of interest that indomethacin, a cyclooxygenase inhibitor, was able to cause potentiation of BK-induced contractions in guinea pig tracheal smooth muscle preparations [18]. These findings may suggest that there could be non-eicosanoid pathways for the cellular and molecular actions of BK.

Furthermore, it is known that BK significantly stimulates phosphoinositide hydrolysis in guinea pig ileum longitudinal muscle that may result in elevation of cytosolic calcium ion levels to induce contractile responses. Schini et al. [19] demonstrated that the $B_{2}$ receptor stimulation causes production of cyclic GMP in cultured porcine aortic endothelial cells. The formation of cyclic GMP may be an important step for the biological actions as well as release of NO evoked by BK in the endothelial cells and in the vascular smooth muscles.

\section{Hypertension and the Kinin System}

Hypertension is a major risk factor in the development of cardiovascular diseases, such as coronary heart disease, congestive heart failure and peripheral vascular \& renal diseases. There is ample evidence documenting the role of $\mathrm{BK}$ in the pathogenesis of hypertension $[2,20]$. The pharmacological actions of BK in regulation of systemic BP are vasodilation in most areas of circulation, reduction in total peripheral vascular resistance and regulation of sodium excretion from the kidney [21]. The role of KKS in hypertension was established by Margolius and co-investigators [22-23] with the observations that urinary kallikrein excretion is significantly reduced in hypertensive patients and hypertensive rats. This led to the suggestion that reduced urinary

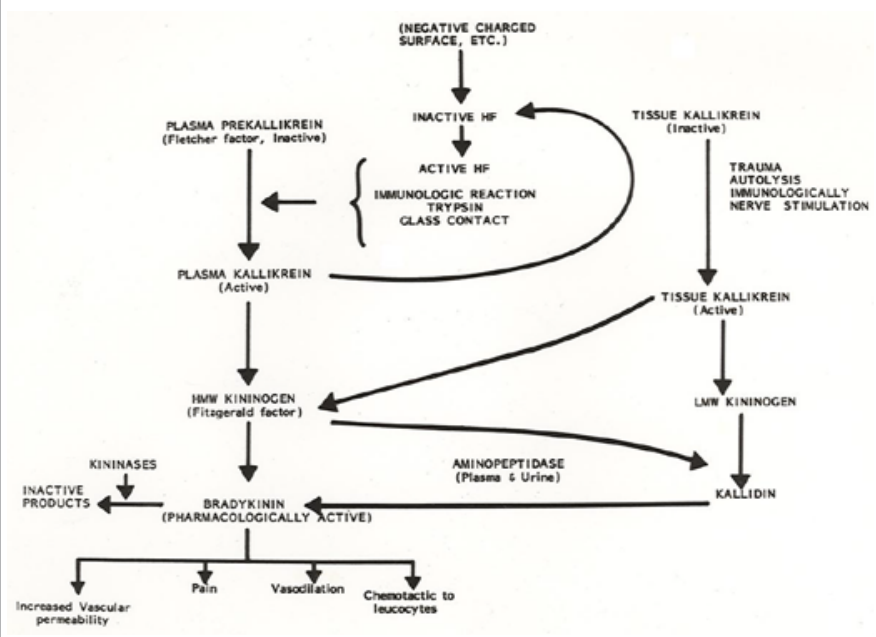

Figure 1: Mode of bradykinin formation and inactivation.

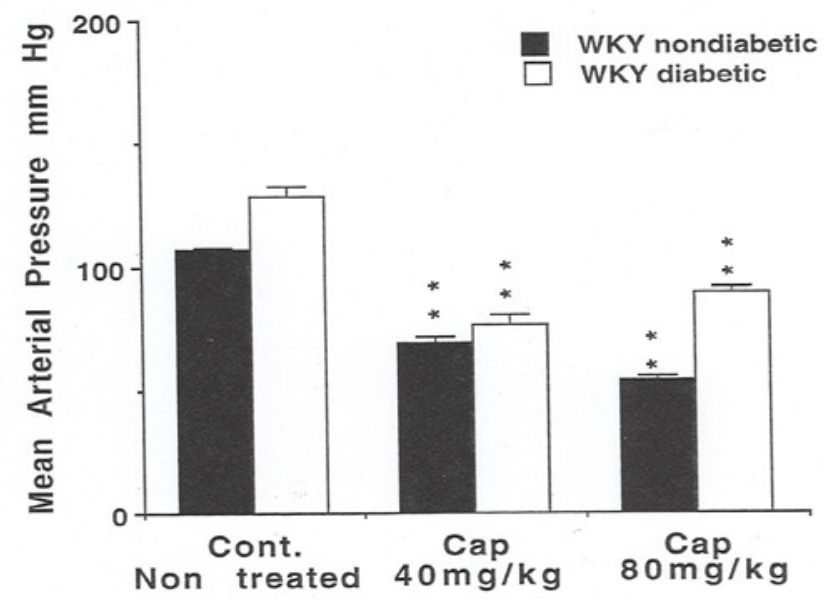

Figure 2: The effect of captopril (cap) treatment $(40 \mathrm{mg} / \mathrm{kg}$ and $80 \mathrm{mg} / \mathrm{kg}$ ) on mean arterial blood pressure (BP) of diabetic and non-diabetic Wistar Kayoto $(\mathrm{WKY})$ rats. The $\mathrm{BP}$ was increased $(\mathrm{P}<0.01)$ in diabetic rats compared to non-diabetic rats. The cap-treated $(40$ and $80 \mathrm{mg} / \mathrm{kg})$ diabetic and nondiabetic rats showed a significant $(p<0.001)$ reduction in BP compared to their respective non treated control (cont) rats. Each column $(n=7)$ represents mean \pm SEM. [57]. 
Citation: Sharma JN, Narayanan P (2011) Hypertension and Diabetes: Contribution of the Kallikrein - Kinin System. J Diabetes Metab S4:004. doi:10.4172/2155-6156.S4-004

kallikrein excretion might result from a reduction in kinin generation in hypertensive situations. Research on the systemic changes in the kallikrein has provided further insight regarding the mechanisms of various hypertensive conditions. In this connection, it is known that kininogen levels and kinin-forming factors are reduced in essential and malignant hypertension [24]. It may be that a deficiency of plasma HMWK due to a decrease in liver synthesis (which decreases kinin production) occurs in an individual who develops hypertension after mild exercise [25]. It is proposed here that a deficiency in BK might be a significant factor in the pathophysiology of hypertension. In this regard, it is suggested that the role of renal BK is to excrete the excess sodium. Therefore, a reduction in the generation of renal BK may be the cause in the development of hypertension as a result of the accumulation of sodium in the body [2]. Thus, the development of a compound having renal kallikrein-like activity may serve the purpose of excreting excessive sodium from the kidney in the treatment of hypertension. Also it has been demonstrated that transgenic mice over-expressing renal tissue kallikrein were hypotensive and that administration of aprotinin, restored the BP of the transgenic mice [6]. We have shown the suppression of hypotensive responses of angiotensin converting enzyme inhibitors (ACEIs) by aprotinin in SHR [26]. These findings highlight a role of tissue kallikrein in the regulation of BP. Recently, it has been proposed that tissue kallikrein gene delivery into various hypertensive models exhibits protection, such as reduction in high $\mathrm{BP}$, attenuation of cardiac hypertrophy, inhibition of renal damage and stenosis [27-30]. Furthermore, gene delivery of kallikrein binding protein re-establishes a normotensive state in tissue kallikrein overexpressing mice [31]. This may indicate the future therapeutics aspect of kallikrein gene therapy for cardiovascular and renal pathology.

ACEIs are currently used in the treatment of both clinical and experimental hypertension [32,33]. ACEIs could lower BP by inhibiting the biodegradation of kinin as well as blocking the formation of angiotensinII (AgII). A calcium-channel blocker, nifedipine, used in treatment of patients with essential hypertension can normalize the reduced urinary kallikrein excretion [34]. Smith et al. [35] have suggested that women with reduced activity of the renal BK may be at increased risk of developing pregnancy-induced hypertension. Previous study has demonstrated that urinary kallikrein excretion was found to be diminished in family members at risk for hereditary hypertension and that urinary kallikrein may be one of the major genetic markers associated with family history of hypertension [36].

$\mathrm{LVH}$ is regarded as an independent risk factor in hypertensive patients in inducing cardiac abnormalities. BK can counter the development of LVH in rats with hypertension produced by aortic banding [37,38]. This anti-hypertrophic effect of BK was abolished by use of a $\mathrm{B}_{2}$ receptor antagonist or inhibitor of $\mathrm{NO}$ formation. Thus, BK has a role in protecting the heart against developing $(\mathrm{LVH})$ by releasing $\mathrm{NO}$ in this model of hypertension induced by aortic banding. In this regard, we have for the first time demonstrated that the lack of the cardiac KKS could be responsible for the induction of LVH in SHR and SHR with diabetes $[39,40]$. It is suggested that the reduced cardiac tissue kallikrein and cardiac kininogen may be responsible for reduced $\mathrm{BK}$ generation in the heart.

Therefore, deficient components of the BK system in the heart may be responsible for inducing excessive hypertrophy and myocardial dysfunction in cases of hypertension. It is highly desirable to develop stable compounds of BK to evaluate their efficacy and potency in cases of cardiac failure, cardiac ischemia and hypertension.

It is the generally accepted view that the BK-induced BP lowering effect is mediated by the $B_{2}$ receptor, but $B_{1}$ receptor might also be involved under special situations [41]. It has been demonstrated that a $B_{2}$ receptor antagonist (B5630) can generally abolish the hypotensive effects of BK as well as captopril, an ACEI [42]. This led to the proposal that the hypotensive action of ACEIs might be due to the activation of $\mathrm{B}_{2}$ receptor. The accumulation of $\mathrm{BK}$ after treatment with ACEIs with subsequent release of NO, prostaglandins (PGs) and prostacyclin $\left(\mathrm{PGI}_{2}\right)$ could account for additional mediators released in the process of anti-hypertensive action of these drugs in hypertensive patients.

\section{Diabetes and the Kinin System}

Several investigators [43-47] have reported alterations of the renal KKS in the diabetic state. Insulin- treated moderately hyperglycemic

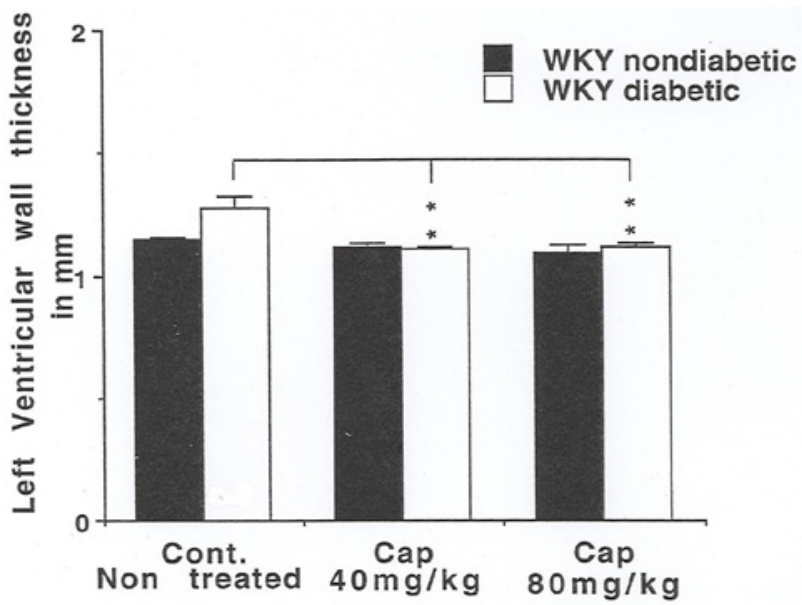

Figure 3: The influence of captopril (cap) treatment (40 and $80 \mathrm{mg} / \mathrm{kg}$ ) on the left ventricular wall thickness (LVWT) of diabetic and non-diabetic Wistar Kyoto $(W K Y)$ rats. Diabetic WKY rats showed a significant $(P<0.01)$ increase in LVWT. The cap- treated (40 and $80 \mathrm{mg} / \mathrm{kg}$ ) diabetic WKY rats produced a significant $(p<0.01)$ reduction in the LVWT compared to the control (cont) diabetic WKY rats. Each column $(n=7)$ represents mean \pm SEM. [57].

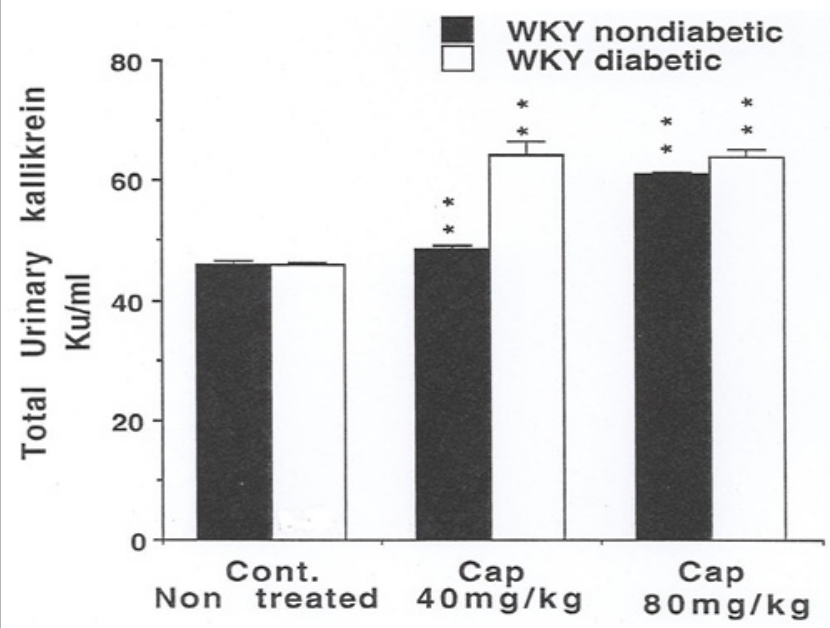

Figure 4: The influence of captopril (cap) treatment $(0$ and $80 \mathrm{mg} / \mathrm{kg})$ on the total urinary kallikrein levels of diabetic and non-diabetic Wistar Kyoto (WKY) rats. The cap- treatment $(40$ and $80 \mathrm{mg} / \mathrm{kg})$ produced a significant $(p<0.001)$ increase in total urinary kallikrein compared to the respective diabetic and non-diabetic control (cont) WKY rats. Each column $(n=7)$ represents mean \pm SEM [57]. 


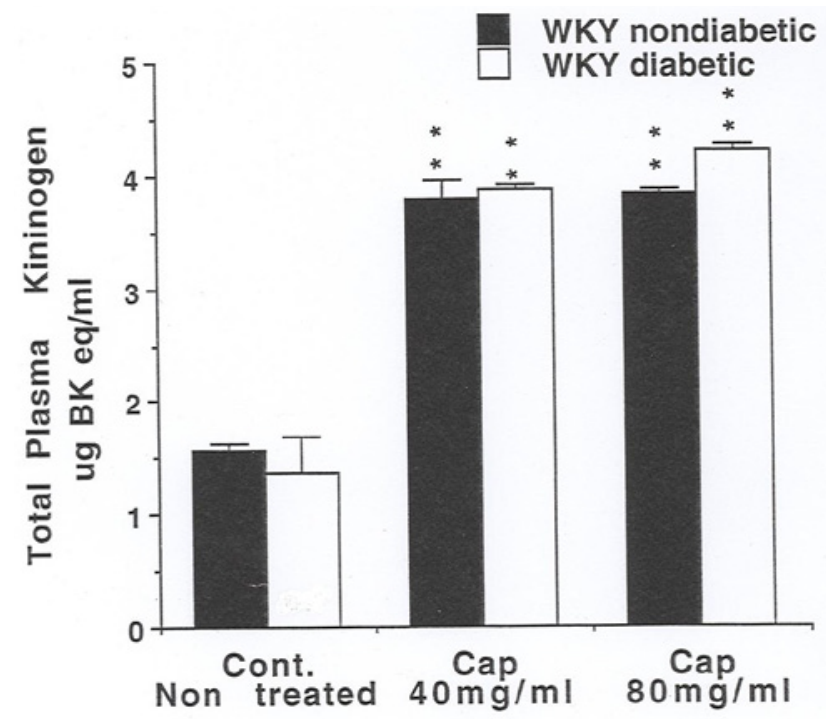

Figure 5: The influence of captopril (cap) treatment (40 and $80 \mathrm{mg} / \mathrm{kg}$ ) on the total plasma kininogen levels of diabetic and non-diabetic Wistar Kyoto (WKY) rats. The cap- treatment $(40$ and $80 \mathrm{mg} / \mathrm{kg})$ produced a significant $(\mathrm{p}<0.001)$ increase in total plasma kininogen levels compared to the respective diabetic and non-diabetic control (cont) WKY rats. Each column $(n=7)$ represents mean \pm SEM [57].

diabetic rats and patients with diabetes mellitus have been reported to show increased urinary kallikrein and BK excretion [44]. These findings suggest that alterations in the kinin-forming components may be the indicator of vascular disease in type 2 diabetics. The renal hyperfiltration in diabetic rats was reduced after pretreatment with aprotinin, suggesting a role of KKS in diabetic state of increased glomerular hemodynamics [48]. In addition, Vieira et al. [49] demonstrated the renal conversion of T-kinin (present in rats) to BK. The conversion of T-kinin, which is the main kinin in inflammation in rats, could be an important alternative pathway for the generation of renal BK in diabetic rats. On the other hand, the metabolism of BK might be impaired and it has to be shown whether changes in the activity of kininases could lead to an increased urinary BK excretion under diabetic conditions. In our earlier studies, we observed the reduction in cardiac and plasma kallikrein and kininogen concentrations in hypertensive and diabetic rats [39]. These studies suggested that the development of LVH and high $\mathrm{BP}$ in these diabetic rats could be the reflection of hypo- activity of the KKS. These research findings were indeed supported by the fact that the reduced synthesis of the myocardial tissue kallikrein implies a reduced capacity to generate $\mathrm{BK}$ in diabetic rats $[45,50,51]$. It can be postulated, therefore, that alterations of the KKS may contribute to the cardiac dysfunction in diabetes mellitus in human patients. Furthermore, it is suggested that treatment with KKS components in diabetic conditions may reverse the myocardial abnormalities observed in diabetic patients. Recently, it has been reported that high plasma prekallikrein activity may serve as a marker for diabetic hypertensive nephropathy [45], which may be the marker of vascular disease in diabetic patients. It has been recently pointed out that cardioprotective effects of the KKS in the diabetic heart suggest that stimulation of the KKS might open new avenues for the treatment of diabetic cardiopathy due to down regulation of kinin inactivating enzymes [10,52,53]. Also, $\mathrm{BK}_{2}$ receptor activation may contribute to the development of diabetic nephropathy [54]. On the other hand, kallikrein gene delivery improves serum glucose and lipid profile and cardiac function in experimental diabetes [55]. Recently, it has been suggested that BK system may be a therapeutic target in preventing and treating diabetic nephropathy [56].

We recently demonstrated that a decrease in tissue kallikrein and plasma kininogen activity in diabetic WK rats may be associated with the development of LVH [57]. Furthermore, treatment with captopril resulted in rise in tissue kallikrein activity as well as kininogen levels in reducing LVH in these diabetic rats (Figures 2-5).

\section{Conclusion}

Abnormal BK components might be responsible for the development of hypertension and diabetes as presented in the review. Drug development to improve the BK functions may help in the treatment of hypertension and diabetes in future. Several investigations are in the progress to establish these facts.

\section{References}

1. Leeb-Lundberg LM, Marceau F, Müller-Esterl W, Pettibone DJ, Zuraw BL (2005) International Union of Pharmacology. XLV. Classification of the kinin receptor family: From Molecular mechanisms to Pathophysiological consequences. Pharmacol Rev 57: 27-77.

2. Katori M, Majima M (2006) Missing link between a high salt intake and blood pressure increase. J Pharmacol Sci 100: 370-390.

3. Linz W, Wiemer G, Schölkens BA (1994) Cardioprotective actions of bradykinin in myocardial ischemia and left ventricular hypertrophy. Braz J Med Bio Res 8: 1949-1954.

4. Sharma JN, Kesavarao U (1996) Cardiac kallikrein in hypertensive and normotensive rats with and without diabetes. Immunopharmacology 33: 341343.

5. Carretero OA (2005) Vascular remodeling and the kallikrein-kinin system. $J$ Clin Invest 115: 588-591.

6. Wang J, Xiong W, Yang Z, Davis T, Dewey MJ, et al. (1994) Human tissue kallikrein induces hypotension in transgenic mice. Hypertension 23: 236-243.

7. Marcondess S, Antunes E (2005) The plasma and tissue kininogen-kallikreinkinin system: role in the cardiovascular system. Cur Med Chem Cardiovasc Hematol Agents 3: 33-44

8. Sharma JN, Uma K, Noor AR, Rahman AR (1996) Blood pressure regulation by the kallikrein-kinin system. Gen Pharmacol 27: 55-63.

9. Moreau ME, Garbacki N, Molinaro G, Brown NJ, Marceau F, et al. (2005) The kallikrein-kinin system: current and future pharmacological targets. J Pharmacol Sci 99: 6-38.

10. Motta G, Rojkjaer R, Hasan AA, Cines DB, Schmaier AH (1998) High molecula weight kininogen regulates prekallikrein assembly and activation on endothelia cells: a novel mechanism for contact activation. Blood 91: 516-528.

11. Rojkjaer R, Hasan AA, Motta G, Schousboe I, Schmaier AH (1998) Factor XI does not initiate prekallikrein activation on endothelial cells. Thromb Haemost 80: $74-81$

12. Shariat-madar Z, Mahdi F, Schmaier AH (2002) Identification and characterization of prolylcarboxypeptidase as an endothelial cell prekallikrein activator. J Biol Chem 277: 17962-17969.

13. Sharma JN (2006) The tissue kallikrein-kininogen-kinin pathways: role in cardiovascular system. Arch Med Res 37: 299-306.

14. Pravenec M, Kren V, Kunes J, Scicli AG, Carretero OA, et al. (1991) Cosegregation of blood pressure with kallikrein gene family polymorphism. Hypertension 17: 242-246.

15. Woolly-Miller C, Chao J, Chao L (1989) Restriction fragment length polymorphism's mapped in spontaneously hypertensive rats using kallikrein probs. J Hypertens 7: 865-871.

16. Farmer SG, Burch RM (1992) Biochemical and molecular pharmacology of kinin receptors. Annual Review of Pharmacology and Toxicology 32: 511-536.

17. Burch RM (1990) Kinin signal transduction: role of phosphoinositides and eicosanoids. J Cardiovasc Pharmacol 15: S44-S45. 
Citation: Sharma JN, Narayanan P (2011) Hypertension and Diabetes: Contribution of the Kallikrein - Kinin System. J Diabetes Metab S4:004. doi:10.4172/2155-6156.S4-004

18. Akbar A, Sharma JN, Yusof AP, Gan EK (1998) Potentiation of bradykinininduced responses in the intact and denuded epithelium of guinea pig tracheal preparations. Int J Tissue React 20: 95-100.

19. Schini VB, Boulanger C, Regoli D, Vonhoutte PM (1990) Bradykinin stimulates the production of cyclicGMP via activation of $B_{2}$ receptors in cultured porcine aortic endothelial cells. J Pharmacol Exp Ther 43: 1823-1827.

20. Sharma JN (2009) Hypertension and bradykinin system. Curr Hypertens Rep 11: 178-181.

21. de Freitas FM, Farraco EZ, De Azevedo DF (1964) General circulatory alterations induced by intravenous infusion of synthetic bradykinin in man. Circulation 29: 66-70

22. Margolius HS, Geller R, De Jong W, Pisano JJ, Sjoerdsma A (1972) Altered urinary kallikrein excretion in rats hypertension. Circ Res 30: 358-362.

23. Margolius HS, Horwwitz D, Pisano JJ, Keiser HR (1974) Urinary kallikrein excretion in hypertensive man: relationship to sodium intake and sodiumretaining steroids. Circ Res 35: 820-825.

24. Almeida FA, Stella RC, Voos A, Ajzen H, Ribeiro AB (1981) Malignant hypertension: a syndrome associated with low plasma kininogen and kinin potentiating factor. Hypertension 3: 46-50.

25. James FW, Donaldson VH (1981) Decreased exercise tolerance and hypertension in severe hereditary deficiency of plasma kininogen. Lancet 1 : 889

26. Sharma JN, Amrah SS, Noor AR (1995) Suppression of hypotensive responses of captopril and enalapril by kallikrein inhibitor aprotinin in spontaneously hypertensive rats. Pharmacology 50: 363-369.

27. Chao J, Chao L (1998) Kallikrein gene therapy in hypertension, cardiovascular and renal diseases. Gene Therapy and Molecular Biology 1: 301-308.

28. Chao J, Chao L (2005) Kallikrein-kinin in stroke, cardiovascular and rena disease. Exp Physiol 90: 291-298

29. Chao J, Bledsoe G, Yin H, Chao L (2006) The tissue kallikrein-kinin system protects against cardiovascular and renal diseases and ischemic stroke independently of blood pressure reduction. Biol Chem 387: 665-675

30. Chao J, Gao L, Hagiwara M, Sen B, Yang Z, et al. (2008) Tissue kallikrein elicits cardioprotection by direct $B_{2}$ receptor activation independent of kinin formation. Hypertension 52: 715-720.

31. Ma JX, Yang Z, Chao J, Chao L (1995) Intramuscular delivery of rat kallikrein binding protein gene reverses hypotension in transgenic mice expressing human tissue kallikrein. J Biol Chem 270: 451-455.

32. Antonacci M (1982) Angiotensin converting enzyme (ACE) inhibitors. Annu Rev Pharmacol Toxicol 22: 57-87.

33. Silberbauer K, Stanek B, Temple H (1982) Acute hypotensive effect of captopril in man modified by prostaglandin synthesis inhibition. Br J Clin Pharmacol 14: 87S-93S.

34. Edery H, Rosenthal T, Amitzur G (1981) The influence of SQ 20881 on the blood kinin system of renal hypertensive patients. Drug in Experimental and Clinical Research VII: 749-756.

35. Smith C, Campbell S, Albano J (1999) Urinary kallikrein excretion in normotensive and hypertensive pregnancies: 8 years later. Immunopharmacology 44: 177182.

36. Kailasam MT, Martinez JA, Cervenka JH, Yen SSC, O'Connor DT, et al. (1998) Racial differences in renal kallikrein excretion: Effect of the ovulatory cycle. Kidney Int 54: 1652-1658

37. Linz W, Wiemer G, Scholkens BA (1993) Bradykinin prevents left ventricular hypertrophy in rats. J Hypertens Suppl 11: S96-S97.
38. Madeddu P, Emanueeli C, El-Dahr S (2007) Mechanisms of disease; tissue kallikrein-kinin system in hypertension and vascular remodeling. Nat Clin Pract Nephrol 3: 208-221.

39. Sharma JN, Uma K, Yusof APM (1998) Left ventricular hypertrophy and its relation to cardiac kinin-forming system in hypertensive and diabetic rats. Int $J$ Cardiol 63: 229-235

40. Sharma JN, Uma K, Yusof APM (1999) Altered cardiac tissue and plasma kininogen levels in hypertensive and diabetic rats. Immunopharmacology 43 : 129-132.

41. Regoli D (1984) Neurohumoral regulation of precapillary vessels: the kallikreinkinin system. J Cardiovasc Pharmacol 6: S401-S412.

42. Sharma JN (2010) Activation of the bradykinin system by angiotensin converting enzyme inhibitors. European Journal of Inflammation 8: 55-61.

43. Jaffa AA, Miller DH, Bailey GS, Chao J, Margolius HS (1987) Abnorma regulation of renal kallikrein in experimental diabetes. J Clin Invest 80: 16511659.

44. Jaffa AA, Rust PF, Mayfield RK (1995) Kinin, a mediator of diabetes induced glomerular hyper filtration. Diabetes 44: 156-160.

45. Jaffa AA, Durazo-Arvizu R, Zheng D, Lackland DT, Srikanth S, et al. (2003) Plasma prekallikrein: a risk marker for hypertension and nephropathy in type diabetes. Diabetes 52: 1215-1221.

46. Harvey JN, Jaffa AA, Margolius HS (1990) Renal kallikrein abnormalities of diabetic kidney. Diabetes 39: 299-303.

47. Platts JK, Meadows P, Harvey JN (1996) The relationship between urinary kallikrein and glomerular filtration rate (GFR) in type-1 diabetes: studies with lithium. Immunopharmacology 33: 351-353.

48. Tschope G, Gavriluk V, Reinecke A (1996) Bradykinin excretion is increased in severely hyperglycemic streptozotocin-diabetic rats. Immunopharmacology 33: 344-348.

49. Vieira MAR, Moreira FM, Maack T (1994) Conversion of T-kinin to bradykinin by the rat kidney. Biochem Pharmacol 47: 1693-1699.

50. Tshope C, Reinecke A, Seidl U, Yu M, Gavriluk V, et al. (1999) Functional, biochemical, and molecular investigations of renal kallikrein-kinin system in diabetic rats. Am J Physiol 277: H2333-H2340.

51. Sharma JN, Kesavarao U (2007) Changes in plasma prekallikrein activity, blood pressure and left ventricular thickness in hypertensive and normotensive diabetic rats. Methods Find Exp Clin Pharmacol 29: 75-78.

52. Spillmann F, Van Linthout S, Schultheiss HP, Tschope C (2006) Cardioprotective mechanisms of the kallikrein-kinin system in diabetic cardiopathy. Curr Opin Nephrol Hypertens 15: 22-29.

53. Koch M, Wendorf M, Dendorfer A, Wolfrum S, Schulze K, et al. (2003) Cardiac kinin level in experimental diabetes mellitus :role of kinases. Am J Physiol Heart Circ Physiol 285: H418-H423.

54. Tan Y, Wang B, Keum JS, Jaffa AA (2005) Mechanisms through which bradykinin promotes glomerular injury in diabetes. Am J Physiol Renal Physio 288: F483-492.

55. Montanari D, Yin H, Dobrzynski E, Agata J, Yoshida H, et al. (2005) Kallikrein gene delivery improves serum glucose and lipid profiles and cardiac function in streptozotocin-induced diabetic rats. Diabetes 54: 1573-1580.

56. Riad A, Zhuo JL, Schultheiss HP, Tschope C (2007) The role of the renal kallikrein-kinin system in diabetic nephropathy. Curr Opin Nephrol Hypertens 16 22-26.

57. Sharma JN Kesavarao U (2011) The effects of captopril on cardiac regression, blood pressure and bradykinin components in diabetic Wistar Kyoto rats. Int J Immunopathol Pharmacol 24: 337-343. 